(RESEARCH ARTICLE)

\title{
Protective effect of Solanum melongena (garden egg), Solanum lycopersicum (tomatoes), Daucus carota subsp. sativus (carrot) extracts on some electrolytes and renal biomarkers of lead induced toxicity in albino wistar rats
}

\author{
Ini P Ekpe*, Dennis Amaechi and Chiwendu Eucharia Obeleagu \\ Biochemistry Department, College of Natural and Applied Sciences, Veritas University (The Catholic University of \\ Nigeria), Bwari, Abuja- Nigeria.
}

Publication history: Received on 10 December 2020; revised on 17 December 2020; accepted on 19 December 2020

Article DOI: https://doi.org/10.30574/wjarr.2020.8.3.0478

\begin{abstract}
The impact of lead toxicity was assessed in this study by analyzing the effects of the extracts on some electrolytes, urea and creatinine concentration. Thirty-five male wistar rats $(150+50 \mathrm{~g})$ were distributed into five groups with seven rats in each group. Extraction and all biochemical analysis were carried out using standard laboratory techniques. Group one served as control, group two as test and were exposed to lead acetate only. Groups three, four and five were treatment groups, administered carrot and garden egg, carrot and tomato, garden egg, carrot and tomato respectively. All groups received feed and water ad libitum. Lead Acetate solution was administered orally at $50 \mathrm{mg} / \mathrm{kg}$ body weight while $200 \mathrm{mg} / \mathrm{kg}$ body weight received mixed juicy extract. On day 15, food was withdrawn, fasted overnight with free access to water. They were euthanized under chloroform vapor and sacrificed. Whole blood was collected via cardiac puncture for biochemical analysis. There was significant $(\mathrm{P}<0.05)$ decrease in potassium and chloride ion in group 2 (test group), compared to the control and treatment groups. Concentration of urea and creatinine in the test group was significantly higher compared with the other groups. Concentration of creatinine in group 3 and 5 significantly increased compared to control group. Effect of lead acetate was significantly reversed in group 5 compared to group 2 . The results of the study indicate the potency of plants extracts against toxicity caused by the lead acetate. Flavonoids, saponins, tannins and alkaloids were present in the extracts.
\end{abstract}

Keywords: Lead Acetate; Creatinine; Extract; Chloroform; Treatment

\section{Introduction}

Lead is a widely used metal, but it is simultaneously a versatile, subtle, and persistent poison. Significant exposure to Lead is an environmental threat to optimal health and physical development in young children and affects all socioeconomic groups. Lead is one of the environmental pollutants that can destroy the life of living creatures in many ways. As a result, humans are exposed by inhalation of polluted air, consumption of contaminated food, water and usage of consumer goods (Sharpe, 2010). Lead is has been associated with human activities for the last 6000 years (Bergdah et al.1997). In ancient civilizations, the uses of Lead included the manufacture of kitchen utensils, trays, and other decorative articles. However, Lead is also toxic to humans, with the most deleterious effects on the hemopoietic, nervous, reproductive systems and the urinary tract (Bergdah et al.1997). Impaired Kidney functions have been reported as one of the most silent feature of Lead toxicity (Chang et al., 1980). Lead nephrotoxicity is characterized by proximal tubular nephropathy, glomerular sclerosis and interstitial fibrosis (Diamond, 2005; Goyer, 1989; Loghman, 1997). Functional deficits in humans that have been associated with excessive Lead exposure include enzymatic, lowand high-molecular-weight proteinuria, impaired transport of organic anions and glucose and depressed glomerular

\footnotetext{
${ }^{*}$ Corresponding author: Ekpe IP

Biochemistry Department, College of Natural and Applied Sciences,Veritas University (The Catholic University of Nigeria), Bwari, Abuja- Nigeria.
} 
filtration rate. A few studies have revealed histopathological features of renal injury in humans including intranuclear inclusion bodies and cellular necrosis in the proximal tubule and interstitial fibrosis (Biagini et al., 1974).

The main sources of Lead exposure are paints, water, food, dust, soil, kitchen utensils, and gasoline. Majority of cases of Lead poisoning are due to oral ingestion and absorption through the gut.

Fruits and vegetables are important for the proper functioning of the body such that they provide essential nutrients and minerals which perform various functions in different parts of the body and are derived from plant origin. These fruits and vegetables have anti-microbial, anti-viral, anti-inflammatory as well as anti-malarial properties which makes it beneficial to the development of drugs and needed to improve human health.

Over the years, plants have been used for different purposes and majority of these plants serve medicinal purposes which made them extremely valuable and readily available. The medicinal and pharmacological properties of plants can be found either in the roots, stem and bark, flowers, seeds, leaves or the entire plant (Fieldsman, 1992). Fruits and vegetables contain different varieties of nutrients including vitamins and minerals such as Vitamins A, C, D, E, calcium, magnesium, zinc etc. They aid in the prevention of diseases usually associated with vitamin deficiency and malnutrition. They contain a variety of phytochemicals (also known as bioactive compounds) recognized for their nutraceutical effects and health benefits.

\section{Material and methods}

All chemicals and reagents used were of analytical grade.

\subsection{Collection and Preparation of fruit extracts}

Fresh Garden Egg, Tomatoes, and Carrot were purchased from Bwari market, Federal Capital Territory, Abuja. The fruits were identified by a botanist from the department of Biological Sciences, Veritas University,Abuja. The samples were washed with deionized water, sliced into pieces with sterile knife. The samples juice was extracted individually using juice extractor. The extracts were then transferred into three separate containers and stored in a refrigerator at 2-5oC.

\subsection{Animals}

Thirty- five healthy male albino Wistar rats with an average weight of $(150 \mathrm{~g})$ were obtained from the animal house of the department of Biochemistry, Ahmadu Bello University,Zaria. They were acclimatized for seven day in the Animal house in Veritas University Abuja during which they had access to food and water ad libitum.

\subsection{Experimental Design}

\begin{tabular}{|l|l|l|}
\hline Rat groups & Mean body weight(g) & Treatment administered \\
\hline 1 & $100.0 \pm 13$ & Normal rat chow and water \\
\hline 2 & $102.3 \pm 12$ & $50 \mathrm{mg} / \mathrm{kg}$ body weight of Lead acetate + Normal rat chow + water \\
\hline 3 & $120.3 \pm 11$ & $\begin{array}{l}50 \mathrm{mg} / \mathrm{kg} \text { body weight of Lead acetate }+200 \mathrm{mg} / \mathrm{kg} \text { of Garden Egg }+ \\
\text { Carrot }+ \text { Normal rat chow }+ \text { water }\end{array}$ \\
\hline 4 & $104.4 \pm 11$ & $\begin{array}{l}50 \mathrm{mg} / \mathrm{kg} \text { body weight of Lead acetate }+200 \mathrm{mg} / \mathrm{kg} \text { of Carrot }+ \\
\text { Tomato }+ \text { Normal rat chow }+ \text { water }\end{array}$ \\
\hline 5 & $88.3 \pm 13$ & $\begin{array}{l}50 \mathrm{mg} / \mathrm{kg} \text { body weight of Lead acetate }+200 \mathrm{mg} / \mathrm{kg} \text { of Garden Egg }+ \\
\text { Carrot }+ \text { Tomato }+ \text { Normal rat chow }+ \text { water }\end{array}$ \\
\hline
\end{tabular}

\subsection{Sample collection and analysis}

All animals were euthanized under chloroform vapor and sacrificed. Whole blood was collected via cardiac puncture using sterile syringes and needle, dispensed into a set of plain tube and allowed to clot for two hours. The clotted blood samples were centrifuged for 10 minutes at $3000 \mathrm{rpm}$ to recover serum from clotted cells. The serum obtained was stored in a refrigerator for biochemical analysis. Biochemical analyses were carried out which include serum electrolytes (Creatinine, urea, potassium and chloride) using Randox test kits. 


\subsection{Statistical analysis}

The results obtained from the laboratory investigation were expressed as Mean \pm SD. Statistical significance between the groups were compared by using one-way analysis of variance (ANOVA) and least significant test (LSD) procedure using the statistical package for the social sciences software (SPSS). The values of $\mathrm{P}<0.05$ was considered to be statistically significant.

\section{Results}

\subsection{Serum analysis concentration}

Potassium concentration was found to be non-significantly $(\mathrm{p}<0.05)$ higher in group 2 (test group) compared to the potassium concentration of group 1 (control), non-significant $(\mathrm{p}<0.05)$ reduction was observed in the potassium concentration of group 4 rats (treatment group administered lead acetate, carrot and tomato) compared to that of group 1. On comparison with group 5 (treatment group given lead acetate, carrot, garden egg and tomato), group 3 rats (treatment group given lead acetate, carrot and garden egg) had potassium concentrations that were found to be nonsignificantly $(\mathrm{p}<0.05)$ higher, while group 1 and 4 recorded a non-significant $(p<0.05)$ decrease.

Urea concentration of group 2 rats (test group) on comparison with the control was observed to be significantly $(\mathrm{p}<0.05)$ higher. Moreover, when compared with group 3 and 5 (treatment groups) had urea concentration that were found to be non-significantly $(\mathrm{p}<0.05)$ higher. Group 4 (treatment group) recorded a non-significant $(\mathrm{p}<0.05)$ decrease in the urea concentration on comparison with the group 1 (control).

Creatinine concentration of group 2 rats (test group) on comparison with the control was observed to be significantly ( $p>0.05$ ) higher. Groups 3, 4 and 5 (treatment group) had creatinine concentration that were found to be nonsignificantly $(\mathrm{p}<0.05)$ reduced when compared to the control.

Table 1 Qualitative Phytochemical composition of S. melongena, S. lycopersicum and Daucus carota subsp.sativus extract.

\begin{tabular}{|l|l|l|l|}
\hline Constituents & S. melongena & S. lycopersicum & Daucus carota subsp.sativus \\
\hline Alkaloids & + & + & +++ \\
\hline Tannins & ++ & ++ & + \\
\hline Flavonoids & + & + & ++++ \\
\hline Saponins & + & + & + \\
\hline Terpenoids & - & + & ++++ \\
\hline
\end{tabular}

Table 2 Electrolytes, Urea and Creatinine Concentration.

\begin{tabular}{|l|l|l|l|l|}
\hline Group & Potassium(K+)mEq/L & Chloride (Cl)mEq/L & Urea (BUN)mmol/L & Creatinine Mg/dL \\
\hline $\begin{array}{l}\text { Group One } \\
\text { (Control) }\end{array}$ & $5.18 \pm 0.32^{\mathrm{c}}$ & $94.15 \pm 0.51^{\mathrm{d}}$ & $4.18 \pm 0.66^{\mathrm{b}}$ & $1.09 \pm 0.33^{\mathrm{a}}$ \\
\hline $\begin{array}{l}\text { Group Two } \\
\text { (Test Group) }\end{array}$ & $2.08 \pm 0.27^{\mathrm{a}}$ & $56.77 \pm 0.76^{\mathrm{d}}$ & $8.30 \pm 1.01^{\mathrm{c}}$ & $2.26 \pm 1.33^{\mathrm{b}}$ \\
\hline $\begin{array}{l}\text { Group Three } \\
\text { (Treatment Group 1) }\end{array}$ & $4.01 \pm 0.15^{\mathrm{b}}$ & $83.86 \pm 0.57^{\mathrm{d}}$ & $6.03 \pm 0.76^{\mathrm{c}}$ & $1.44 \pm 0.77^{\mathrm{a}}$ \\
\hline $\begin{array}{l}\text { Group Four } \\
\text { (Treatment Group 2) }\end{array}$ & $5.02 \pm 0.45^{\mathrm{c}}$ & $74.82 \pm 1.30^{\mathrm{d}}$ & $4.41 \pm 2.03^{\mathrm{b}}$ & $1.13 \pm 1.53^{\mathrm{a}}$ \\
\hline $\begin{array}{l}\text { Group } \\
\text { Five(Treatment } \\
\text { Group 3) }\end{array}$ & $3.89 \pm 1.03^{\mathrm{b}}$ & $76.35 \pm 0.67^{\mathrm{d}}$ & $6.08 \pm 0.83^{\mathrm{c}}$ & $1.33 \pm 0.49^{\mathrm{a}}$ \\
\hline
\end{tabular}

Values are expressed as Mean \pm SD at significant level of $p<0.05$. Values on the same column with the same superscript are statistically not different whereas values on the same column with different superscript are significantly different. $\mathrm{P} \geq 0.01 \mathrm{n}=3$; Values are presented \pm standard error of mean (SEM); $\mathrm{a}=$ values are significantly lower than the values down or within the treatment column; b, $c, d, e=$ values are significantly higher than the values before or within it in the treatment column 


\section{Results and Discussion}

Table 1 shows results of phytochemicals analysis which revealed the presence of Flavonoids, Phenol, Alkaloids, Tannins and Saponins in the extracts of S. melongena, S. lycopersicum, Daucus carota subsp.sativus. The presence of these phytochemicals in the extracts is in line with the report of Okwu (2013). The egg plant species and carrots contained a significant amount of alkaloids which is known to give the plant its bitter taste. These alkaloids present makes the fruit highly medicinal and nutritional. Alkaloids acts protective substance against animal or insect attacks in man, and like hormones, they function as plant regulator (Gutlendge, 2011).

Tannins were found to be slightly present in the all the plants although slightly present in garden egg. The astringency from tannin is known to cause the pucker and dry feeling in the mouth which follows the consumption of unripe fruits (Westman, 2013). Foods rich in tannin can be used in treatment of hemochromatosis.

Flavonoids were found to be present in the three plants under study. Flavonoids has a wild range of biological and pharmacological activities which include antioxidant, anti-microbial and anti-inflammatory activities (Mc Naught, 2015). Flavonoids are also responsible for the coloring of most fruits.

Saponins were found present in all the plants under study. Saponins are well known by their froth foaming produced when shaken in aqueous solution. Saponins promotes cardiovascular health due to their ability to lower cholesterol and body fat level. Due to their hypoglycemic properties they have beneficial effect on body weight. Saponins exhibits antimicrobial properties which guards the body system against fungi, bacteria and viruses. (Hasslam, 2017).

Table 2 shows result of electrolytes in the different groups. The impact of Lead toxicity was assessed in this study by analyzing some electrolytes concentration (Potassium and Chloride) and renal function tests for urea and creatinine which serves as some of the biomarkers for kidney damage respectively. The degeneration and destruction observed in the renal tissues can be associated to the generation of reactive oxygen species (Sharma et al., 2012; Singh et al., 2012). The rise in the concentration creatinine and urea in the groups administered with the Lead acetate was good enough to categorically state that the chemical is possibly nephrotoxic. The level of creatinine $(2.26 \pm 1.33 \mathrm{Mg} / \mathrm{dL})$ and $\mathrm{urea}(8.30$ $\pm 1.01 \mathrm{mmol} / \mathrm{L})$ in the serum of group 2 rats appears to be abnormally higher than the normal range, $(0.50-0.90 \mathrm{Mg} / \mathrm{dL})$ for creatinine and $(1.8-7.1 \mathrm{mmol} / \mathrm{L})$ for urea, compared to the control as caused by Lead acetate toxicity. Accumulation of the Lead in the blood caused a damage to the kidney function that results to the reduced ability of the kidney to effectively excrete the excess through the urinary tract. The rat group(s) 3,4,5 administered with the plants extracts after they were intoxicated with Lead acetate showed a decrease the levels of the renal parameters; For group 3 level of urea $(6.03 \pm 0.76 \mathrm{mmol} / \mathrm{L})$, creatinine $(1.44 \pm 0.77 \mathrm{Mg} / \mathrm{dL})$, for group 4 level of urea $(4.41 \pm 2.03 \mathrm{mmol} / \mathrm{L})$, creatinine $(1.13 \pm 1.53 \mathrm{Mg} / \mathrm{dL})$, for group 5 level of urea $(6.08 \pm 0.83 \mathrm{mmol} / \mathrm{L})$, creatinine $(1.33 \pm 0.49 \mathrm{Mg} / \mathrm{dL})$, compared to the group 2 rats, level of urea $(8.30 \pm 1.01 \mathrm{mmol} / \mathrm{L})$, creatinine $(2.26 \pm 1.33 \mathrm{Mg} / \mathrm{dL})$. This may be due to the potency of the plants against Lead intoxication that led to the revitalization of the kidney.

Imbalance in serum electrolytes is an important indicator of toxicity in identifying target organs and general health status of animals. In group 2 there was decrease in serum electrolyte concentrations of potassium $(2.08 \pm 0.27 \mathrm{mEq} / \mathrm{L})$ and chloride $(56.77 \pm 0.76 \mathrm{mEq} / \mathrm{L})$ compared to the normal range $(3.4-5.3 \mathrm{mEq} / \mathrm{L})$ for potassium and $(98-106 \mathrm{mEq} / \mathrm{L})$ for chloride. It is an indication in perturbation of electrolytes metabolism due to exposure to Lead thus resulting in alterations in cellular functions in which these electrolytes are involved.

Electrolytes plays significant role in several body processes, such as controlling fluid levels, acid-base balance ( $\mathrm{pH}$ ), nerve conduction, coagulation and muscle contraction (Hasona and Elasbali, 2016). Fluid and electrolytes homeostasis are usually maintained within narrow limits (Roberts, 2005) and therefore, it must be kept at a level that is suitable for normal biochemical and physiological functions (Kaneko et al., 2008).

So many severe environmental and health hazards have been associated to the utilization of compounds such as Lead through oral ingestion and other routes of exposure. Aly and El-Gendy, 2000 stated the negative effect of such compounds on the liver, kidney, nervous system, immune system and reproductive system. This indicates the toxicity potential of the compounds which varies depending on the class, biological activities and the different antagonistic effects they cause in living organisms including man. The biochemical basis of Lead toxicity is fundamental to understanding serum electrolytes alterations in Lead-exposed patients. This is important with a view to proposing alternatives to diagnosis, treatment and prevention of Lead poisoning menace (Idoko et al., 2018). 
In this study, Lead was reported to cause alterations in the electrolytes in these organs. It was reported that one of the potential mechanisms by which Lead exhibit its toxicity is by inhibition of ATPases which is a membrane bound enzymes. It could be that inhibition of these ATPases activities which is responsible for electrolytes movement was overwhelmed resulting in alterations of electrolytes in these organs studied. Also, since membrane is made up of lipids there is every possibility that Lead alters the membrane structure and could trigger lipid peroxidation thus disturbing the ATPases conformation and configuration thereby distorting movement of electrolytes. (Carafoli, 1987), reported inhibition of $\mathrm{Ca} 2+, \mathrm{Mg} 2+$ ATPases activities, while (Guzide et al., 2003), reported inhibition of Na+, K+ ATPase and Ca2+, $\mathrm{Mg} 2+$ ATPases activities, transport proteins, which regulate cations flux involved in maintaining and regulating intracellular cation content by Lead. The low levels of potassium in blood is due to the sodium-potassium pumps in cell membranes, which maintain the normal potassium concentration gradients between the intra and extra-cellular fluid. This low levels of potassium in the blood may result to a condition known as Hypokalemia. The treatment groups 3, 4 and 5 showed the electrolytes levels less than that of the control. This may confer to the effects of the administered plants extracts that possess a characteristic bioactive compound with the potency to reduce renal damage. This is relative to the findings of Okediran et al., 2019.

It was observed from this study that the plants extracts showed their potential in the reduction of elevated renal biomarkers and also played enormous role in the regeneration of the kidney damaged by Lead acetate exposure probably due to the effect of bioactive compounds such as the phytochemicals such as flavonoids, saponins, alkaloids and tannins contained in them.

\section{Conclusion}

This study was carried out to determine the effect of Solanum melongena (Garden Egg), Solanum lycopersicum (Tomatoes) and Daucus carota Subsp. Sativus (Carrot) extracts on some electrolytes of Lead induced toxicity in albino wistar rats. This was carried out by analyzing the effects of the extracts on potassium, chloride, urea and creatinine concentrations in the blood. The results of the study indicate the potency of the plants extracts against toxicity caused by the Lead acetate. The study also revealed the deleterious effect of Lead acetate exposure to kidney and some selected electrolytes of the living system. This was confirmed by the assay of some biomarkers. Reports show that these plants contain some phytochemical compounds. Thus, the extracts possess anti-nephrotoxic potential which is dependent on its bioactive compounds. This study has shown that the used plants could regulate and reduce elevated renal biomarkers in individuals that are in constant exposure to Lead. It can therefore be assumed that any of these plants is equally effective in ameliorating Lead acetate toxicity.

\section{Compliance with ethical standards}

\section{Acknowledgments}

Acknowledgments to Veritas University, Abuja.

\section{Disclosure of conflict of interest}

There is no conflict of interest among the authors.

\section{Statement of ethical approval}

The present research work contained studies on experimental animals (albino wistar rats). They were obtained from the disease-free stock of the animal house of the department of Biochemistry, Ahmadu Bello University,Zaria. The animals were housed in in standard cages, exposed to 12 hour light and dark cycle. They were properly handled by feeding with grower feed pellets and water ad libitum. Proper hygiene and good ventilation were maintained.

\section{References}

[1] Bergdahl I, Schutz A, Gerhardsson L. Lead concentrations in human plasma, urine and whole blood. Scand J Work Environ Health. 1997; 23: 359-363.

[2] Biagini G, Caudarelia R, Vangelista A. Renal morphological and functional modification in chronic Lead poisoning. In: Brown SS, ed. Clinical chemistry and chemical toxicology of metals. Elsevier/North Holland Biomedical Press. 1977; 123-126.

[3] Carafoli E. Intracellular calcium homeostasis. Annual Rev. of Biochem. 1987; 56: 395-433. 
[4] Chang LW, Wade PR, Olson MN. Ultrastructural changes in renal proximal tubules after tetraethyle Lead intoxication. Environ. Res. 1980; 23(1); 208-23.

[5] Diamond GL. Risk assessment of nephrotoxic metals. In: Tarloff, J, Lash L, edition. The toxicology of the kidney. London. CRC Press. 2005; 1099-1132.

[6] Fieldsman N, Slimani M, Aoues A. Effect of Lead exposure on dopaminergic transmission in the rat brain; Toxicol. 1992; 207: 363-369.

[7] Goyer RA. Mechanisms of Lead and cadmium nephrotoxicity. Toxicology.Lett. 1989; 46:153-162.

[8] Gutlendge AS. Introduction to the Chemistry of Natural Compounds. American Journal of Natural Compound. 2011; 10 6): 228-239.

[9] Guzide Y, Ramazan R, Lulufer T, Seyham T. Effects of Lead on Na+-K+- ATPase and Ca2+-ATPase activities and lipid peroxidation in blood of workers. International Journal of Toxicology. 2003; 22(2): 95-97.

[10] Hasslam E. Natural Poly-phenols as Possible Mode of Action. Journal of Natural Product. 2017; 59(13): $205-215$.

[11] Hasona NA, Elasbali A. Evaluation of electrolytes imbalance and dyslipidaemia in diabetic patients. Med Sci. 2016; $4(2): 1-4$.

[12] Nemsadze K, Sanikidze T, Ratiani L, Gabunia L, Sharashenidze T. Mechanism of Lead-induced poisoning. Georgian Medical News. 2009;(172-173):92-6.

[13] Kaneko JJ, Harvey JW, Bruss ML. Clinical Biochemistry of Domestic Animals, (6th Ed.). Academic, London. 2008; 117-138.

[14] Loghman-Adham M. Renal effects of environmental and occupational Lead exposure Environ. Health Perspect. 1997; 105: 928-939.

[15] McNaught KM. Phytochemical and Human Health. Journal of the Italian Pharmacological Society. 2015; 55(3): 207-216.

[16] Okediran M, Kawamura NS. Early appearance and localization of intranuclear inclusions in the segments of renal proximal tubules of rats following ingestion of Lead. Br. J. Exp. Pathology. 1983; 64: 144-155.

[17] Okwu, DE. Evaluation of the Phytonutrients, Mineral and Vitamin Content of S. melongena. International Journal of Molecular Medicine and Advances in Science. 2013; 22: 1999-203.

[18] Roberts, KE. Pediatric fluid and Electrolytes Balance: Critical Care Case Studies. Critical Care Nursing Clinic Norway. 2005; 17(4): 361-373.

[19] Sharma KD, Karki S, Thakur NS, Attri S. Chemical composition, functional properties and processing of carrot. Journal of Food Science and Technology. 2012; 49:22-32.

[20] Singh DP, Beloy J, McInerney JK, Day L. Impact of boron, calcium and genetic factors on vitamin C, carotenoids, phenolic acids, anthocyanins and antioxidant capacity of carrots (Daucus carota). Food Chemistry. 2012; 132: 1161-1170.

[21] Westman C. Industrial Organic Chemistry, 3rd Edition, Springer Verlag press, New York. 2013; $148-155$. 